\title{
PROCEEDINGS OF THE FIFTY-NINTH ANNUAL MEETING OF THE AMERICAN SOCIETY FOR CLINICAL INVESTIGATION, INC., HELD IN ATLANTIC CITY, N. J., MAY 1, 1967
}

\author{
Presidential Address
}

\section{The Mores of Clinical Investigation}

\author{
Grant W. LidDLe
}

During recent years public discussion concerning the mores of clinical investigation has reached such a crescendo that the time has come for us as clinical investigators to define the mores that govern our actions.

The word mores has been chosen deliberately, and I inend to use it precisely as sociologists do in referring to a mechanism of social control. It is the sum total of those attitudes within a community that imply, "If you do this, we shall approve; if you do that, we shall disapprove." The sociologist's term mores is to be distinguished from the philosopher's term ethics, which is concerned with the general principles of evaluation of mores.

As a result of recent developments in scientific knowledge and shifts in social values, many situations now arise in which customary practice is not a sufficient guide to appropriate conduct for the physician. However, it is possible that some of the current bewilderment and some of the controversies about the changing mores of clinical investigation could be dispelled if we had a clear view of the existing mores and their relative importance.

There has never been a moral vacuum surrounding the clinical investigator. The clinical investigator is, of course, governed by the mores that apply to all citizens; but, in addition, he is governed by mores that apply specifically to the physician and those that apply to the scientist. The morality of clinical investigation has its ultimate base in the attitudes of society in general, and it is our responsibility to understand as clearly as possible what society expects of us. Since not all of society's expectations carry equal force, the relative importance of various mores must be kept in proper perspective when they are applied to practical situations. If various mores are mutually inconsistent, we should provide responsible leadership in recognizing the inconsistencies and resolving them.

Let us enumerate the mores of the physician. First, the physician must do no harm. Second, the physician must do whatever is within his power to protect and improve the health of his patient. I submit that these first two mores are universally held and are as old as the art of medicine. Last year this Society formally and unanimously endorsed the Declaration of Helsinki, which begins with the statement, "It is the mission of the doctor to safeguard the health of the people. His knowledge and conscience are dedicated to the fulfillment of this mission." The knowledgeable and conscientious physician who is faced only with familiar problems should have no difficulty conforming to the mores of the physician. When the physician is faced with a situation in which the best course of action cannot be determined because of his limited knowledge, he has an obligation to augment his knowledge so that the benefits and risks of a particular regimen are as predictable as possible. When he is faced with a situation in which there is doubt as to what to do because social values are ill defined, the physician should consult not only other physicians but also responsible lay people in trying to arrive at a morally acceptable course of action.

The physician's third moral obligation is neither universally held nor very old. It is the requirement that he obtain the informed consent of his patient. The "informed consent" rule has caused concern among many responsible physicians because it is in potential conflict with the traditional mores that require the physician to protect his patient from harm and to restore his health. What is one's duty when the very act of "informing" the patient might be contrary to the patient's best interests? The patient-physician relationship is not a forensic one. Not many patients wish or expect to engage in a dialogue as to what is good for them. Every experienced physician who has attempted to explain the relative merits of alternative courses of treatment to his patients has found himself interrupted by a patient's statement that he merely wishes to follow the regimen that the physician considers best. Certainly it is usually desirable to keep patients well informed, but according to the traditional mores of society, the patient, if he wishes, has a right to depend entirely upon the knowledge and conscience of his physician. The patient has the right to give his uninformed consent if he wishes. The sick patient who is unable to comprehend or unable to give consent is still entitled to receive the best care the physician can give him; in this situation we must assume that consent is implied. The physician's obligation to do what is best for his patient is the same regardless of whether the patient's consent is informed, uninformed, or only implied. It is the same whether treatment is new or old; it is the same whether scientific observations are recorded or not. Ordinarily, the patient should be given all the information necessary to enable him to make responsible judgments. Bevond that. he is entitled to all 
the information he wishes. But in those situations in which such information would bring harm to the patient, the physician has an obligation not to seek informed consent. As will be emphasized shortly, the informed consent rule is essential in connection with procedures that are performed solely for the purpose of obtaining scientific information, but it should not be permitted to interfere with the proper care of a sick person.

The authors of the Declaration of Helsinki did not intend that the "informed consent" rule should take precedence over the traditional mores of the physician. The Declaration states, "In the treatment of the sick person, the doctor must be free to use a new therapeutic measure, if in his judgment it offers hope of saving life, reestablishing health, or alleviating suffering. If at all possible, consistent with patient psychology, the doctor should obtain the patient's freely given consent after the patient has been given a full explanation." Clearly, the authors of the Declaration of Helsinki were echoing the traditional mores of the physician. It is the first duty of the physician to protect the health and the psychological integrity of his patient. All other considerations must be secondary. We must educate rulemakers and lawyers that "informed consent" is not an end in itself but the total well-being of the patient is.

An important distinction is made in the Declaration of Helsinki between the research subject who might reasonably be expected to benefit from a study and the research subject for whom no such benefit can be anticipated. The essential question is not whether the physician makes observations that might have scientific value; it is whether the procedure to be employed has been selected on the basis that it is the one most likely to benefit the patient. If the patient's well-being is the first consideration, then the question of informed consent is secondary.

However, when the purpose of the study is purely scientific, whether the subject is a healthy volunteer or a sick patient, "the nature, the purpose, and the risk" of the study "must be explained to the subject by the doctor." Without the free consent of the subject the purely scientific study cannot be undertaken. Here there is no question about the compound nature of the physician's obligation. He must obtain informed consent, and he must stand by the subject to protect him from harm. We live in a society that considers it unacceptable for one to use another's property without obtaining his consent. Certainly, then, it is morally offensive for one to use another's person without first obtaining his informed consent.

Even though it is ordinarily desirable to keep the patient well informed, the responsibility for professional judgments cannot be shifted to the patient. If the responsibility for professional judgments must remain with the physician and if we concede that no physician is infallible, what can be done to minimize the likelihood of imprudent medical practice? One system is to surround the individual practitioner by other knowledgeable and responsible physicians, thus establishing a truly informed moral community. The academic physician, surrounded as he is by talented consultants and living in a "glass house," is in an optimal position to perform the doctor's traditional mission of protecting the health of the people. By precept and example, he should make it so clear that he is adequately playing his role that there will never be a vacuum of responsibility into which others, less capable, might move.

Who can do most to enforce these mores? Everyone has a share of the responsibility. There is no substitute for moral sensitivity on the part of every physician, but in any moral community there are some who hold special positions of responsibility. When it comes to insuring the quality of patient care, department heads, service chiefs, directors of research and training programs, and peer groups have particular responsibility. They are in positions to observe the conduct and attitudes of physicians on their staffs. They are in positions of esteem, so that their counsel will usually be heeded, and they are in positions to give or withhold staff privileges.

So much for the mores of the physician; in addition to these mores, the clinical investigator is expected to observe the mores of the scientist. What does society expect of us if we are to maintain good standing as investigators? First, society expects that every investigator who contributes a fact or concept to the fabric of interdependent functions that we call "clinical science" shall be absolutely trustworthy. No one has access to absolute truth, but clinical investigators should be able to design experiments that are controlled so as to eliminate subjectivity, bias, and "noise." Measurements must be made with competence and observations recorded with scrupulous care. Inferences must be clear declarations of what has been proved by the experiment. Speculation beyond the immediate content of the study is laudable only if it is labeled as speculation and conveys useful perspective by indicating how a particular experiment is related to what is already known or believed.

Second, the clinical scientist must be creative. In the words of the Declaration of Helsinki, "It is essential that the results of laboratory experiments be applied to human beings to further scientific knowledge and to help suffering humanity." Just as the physician is expected "to safeguard the health of the people" of today, the physician-scientist is expected to safeguard the health of the people of the future. The investigator in good standing is one who is actively enriching clinical science with sound new concepts of human biology. The clinical investigator is expected to address himself to important problems and to ask questions in such a way that they will yield meaningful answers.

If the first moral obligation of the scientist is to be trustworthy and the second is to be creative, then third is the obligation to communicate. Clinical investigation is not a private affair. Those who support our research units have a right to know what they are paying for. And those investigators who are to be identified as creative scientists must document their creativity in the form of publications and presentations that can withstand critical scrutiny. The very viability of science depends upon our effective exchange of data and ideas. Scientific publication permits the participation of many minds in 
the solution of problems. The emergence of science would have been impossible without the printing press, and, without the printing press, science would quickly return to the nothingness of the Dark Ages. Science is a social enterprise. If we fail to communicate, we fail to contribute.

Who is responsible for enforcing the mores of the clinical scientist? All clinical investigators share this responsibility. I think the principle justification for the existence of The American Society for Clinical Investigation, of The Journal of Clinical Investigation, and of this Annual Meeting is to demonstrate that clinical investigators do place high value on trustworthiness, creativity, and communicativeness in clinical science. No one here has escaped noticing that clinical investigators do form a moral community, that they do have ways of expressing favor or disfavor, and that those who earn approval are those whose work is trusted, creative, and effectively communicated.

Society has given clinical investigators the unique mission of providing the scientific basis for a better medicine of tomorrow. We have been given enough moral support to inspire the creativity needed to fulfill this mission, enough economic support to implement it, and, ironically, enough well-intentioned but encumbering regulations to stifle it. Again, we must make a responsible interpretation of what society expects of us. If we allow ourselves to be more concerned with "percentage of effort reports" than with what comes of our efforts, or more concerned about obtaining the written consent of patients than about helping them, or more concerned about conforming to regulations than about getting a job done, then we shall have failed to place the expectations of society in proper perspective. We must assume that society sanctions scientific creativity and does not intend to have the creativity of the clinical investigator stifled by procedural details. Whenever possible we should convey this moral perspective to the legislators and the administrators who translate mores into the regulations governing clinical investigation. As individuals and as an organization we should use every opportunity to maintain bidirectional communication with those who shape the attitudes of society as well as with those who respond to pressures from society by writing laws and regulations. On the one hand, we must understand society's hopes and concerns about clinical investigation; on the other, we must ac- quaint society with the purposes, the achievements, the potential, and the basic needs of clinical investigators. It is important for everyone to understand that the quality of tomorrow's medicine will depend upon the creativity of today's clinical investigators and that, to be creative, clinical investigators need all of the support and all of the freedom society can afford.

Since the clinical investigator must obviously be governed by the mores of the physician and those of the scientist, we might try to see whether they can be integrated in a hierarchy. Foremost stand the physician's traditional charges to do no harm and to protect the health of the patients. If the obligation to obtain "informed consent" comes into conflict with these traditional charges, then the health of our patients must take precedence. As scientists, we also have a duty to be creative, but when this conflicts with the health of our patients, the health of our patients must take precedence. If the clinical investigator cannot be creative without neglecting his patients, then he should share or reduce his clinical responsibilities so that scientific creativity and excellent patient care go hand-in-hand. If our obligation to be creative comes into conflict with our obligation to obtain the informed consent of subjects, then the rights of our subjects must take precedence. We are asked to conform to numerous administrative regulations, but, when doing so conflicts either with the health of our patients or with our duty to be creative, the regulations should be changed. For the health of our patients today and the creativity that will secure the health of our patients tomorrow are ends in themselves; administrative procedures should be means to these ends.

Although this hierarchy of mores might seem clear enough in the abstract, such a neat arrangement of moral values is sometimes difficult to apply to concrete situations. But as long as we are responsive to the expectations of society, we have a right to expect, in return, understanding and support from society. Society has given us the mission of providing the scientific basis for securing better health for the people of tomorrow. In accepting this mission we live by a set of mores that no one here disputes. As long as we live by these mores, let society give us the support and freedom we need, to help and not to hinder us, in fulfilling the mission they have given us. 